\title{
Towards a Guideline for Design of a Corporate Entrepreneurship Function for Business Development in Medium- Sized Technology-Based Companies
}

\author{
Boaz Uittenbogaard, Lute Broens and Aard J. Groen
}

The speed with which global high-technology markets evolve makes companies recognize that an effective innovation process is the best way to guarantee competitiveness. However, when (medium-sized) companies then wish to set up a corporate entrepreneurship function to enhance business development processes, they can find little material available in literature to assist in such processes. In this article we have described a guideline and some backgrounds for creating a corporate entrepreneurship function to realize business development in a hightech context.

\begin{abstract}
A $t$ this moment, there is no general guideline on how to develop an effective corporate entrepreneurship function (CEF) in a medium-sized technology-based company available in literature. So, the first contribution is to construct such a guideline based on elements of the body of knowledge in this area. In this article we touch upon the construction process of such a guideline. Using as a basis the $4 \mathrm{~S}$ social system perspective, adding several literary sources for further operationalization of elements, and data on five large hightech companies, we found a list of success and fail factors for creating a CEF. The empirical study by Leleux, Tindemans and Gosselin (2001) corroborated most findings. Based on five cases used for developing the guideline it should be noted that the business processes and competitive environment are different in every organization. Still, the communalities in the cases and elements found in literature make it justifiable to assume that the presented guideline contains elements that are crucial in every 'process of structuring innovation'.

The case study of Process ${ }^{\mathrm{TM}}$ shows that also in this case all elements point out relevant questions for the management of the CEF. Although only applied to this one case, the theoretical background and the results in this case suggest that this guideline can also be applied to other medium-sized or large com-
\end{abstract}

panies that wish to create structured business development processes. However, this guideline is neither a ' 10 steps to success' - model, nor a summary of ideas that business development managers can interpret any way they want to. It shows a sequence of factors that has to be considered in the process of implementing a suitable business development process and matching environment.

\section{Introduction}

From Schumpeter (1934) to contemporary theorists such as Christensen (2003), claims have been made that innovation is a crucial process for economic development. The seminal work of these authors, and work of many others, has shown that new technology is a resource for innovation and business development. In this article we will address contemporary approaches of organizations trying to create an innovative organization where new business is developed. Whereas in management of technology literature much attention has been paid to R \& D organization, little attention has been paid to the organization of business development or as it also referred to, of corporate entrepreneurship.

We notice in practice that in the past few years large multinational companies have 
acknowledged the need for structured innovation and have created separate business development departments to fulfill this need. Examples of such departments in Dutch multinational companies can be found at DSM (DSM Venturing \& Business Development) and Philips (Philips Corporate Incubator). The purpose of these departments is to maintain and improve competitiveness through the development of new product-market combinations or in other words to stimulate corporate entrepreneurship. Medium-sized companies also begin to realize that organized innovation is the key to success in today's quickly developing high-tech markets and find that corporate entrepreneurship and business development are the concepts that should lead them to the status of 'innovator'. In this article we will focus on a company, Process ${ }^{\mathrm{TM}}$, that has expressed the desire to become market leader through innovation, but is experiencing difficulties in how to establish the right balance between managing the 'everyday business' and creating a highly innovative environment that will lead them to the 'top'. The company aims to establish this balance through the creation of a business development function.

The goal of this article is to contribute to (design) knowledge on organizing a corporate entrepreneurship function in medium-sized companies. The principal research question is: how can an effective corporate entrepreneurship function (CEF) be developed in a medium-sized technology-based company?

The research performed to answer this question entailed first a literature study and an analysis of five cases in Dutch multinational firms. We will only summarize this in the first part of this article, the 'background study', because of place restrictions. In the second part of the article a 'Guideline for structured innovation' will be presented that combines the findings of our literature study and our research outcomes into a toolset for Process ${ }^{\mathrm{TM}}$. This guideline will be applied in the third section: the case study. The conclusion and discussion is subject of the last part.

\section{Background Study}

In this part we present our conclusions from a literature search looking for the body of knowledge on organizing the corporate entrepreneurship function. Definitions of business development and corporate entrepreneurship functions will be given, and some important aspects of corporate entrepreneurship will be presented, as well as some success and failure factors found in literature. The second part of the background is based on an analysis of five cases of large firms organizing the corporate entrepreneurship function.

\section{Developing a Framework of \\ Corporate Entrepreneurship}

We start by presenting definitions of the terms 'business development' and 'corporate entrepreneurship function' as they will be used here. Since both terms have many interfaces in the way they are used by various authors, it is important to understand the differences and the relation between them.

Based on various definitions (for example, Badguerahanian \& Abetti, 1995; Barringer \& Bluedorn, 1999; Saly, 2001; Thornberry, 2002), the following relation between business development and the corporate entrepreneurship function can be defined: business development involves the actual development of product-market combinations, in other words it involves the 'execution of the innovation process'. It could be organized as a dispersed process throughout the company. The corporate entrepreneurship function (CEF) involves the way the organization is shaped around the innovation process in order to create, maintain or improve innovativeness and business development. In the CEF, companies organize the process to deal with the tensions between exploitation and exploration (March, 1991) or, in other words, firms create the necessary strategic flexibility while maintaining operational effectiveness (Groen, During \& Weaver, 2002; Weerd-Nederhof, 1998).

The Weerd-Nederhof's (1998) framework for analysing the value of R\&D is also applicable for analysing the performance of the corporate entrepreneurship processes. It is inspired by social system theory on creation and maintenance of sustainable 'units' in a space of connected functionalistic actors. In this article the focal unit is a firm. The social system perspective focuses attention on four dimensions: goal attainment (strategy), pattern maintenance (skills, values, arrangements), adaptation for efficiency (scale) and integration into networks with other actors (social networking) (see also Groen, 2005). Combining this with different emphases of a number of authors on both business development and corporate entrepreneurship issues, the following aspects seem to be important.

\section{Strategic Issues Related to Goal Attainment: Business Development Mission}

This aspect refers to the desired level of impact of the company's entrepreneurial activities on the organization and industry. Both Rip and Groen (2001) and Thornberry (2002) distin- 


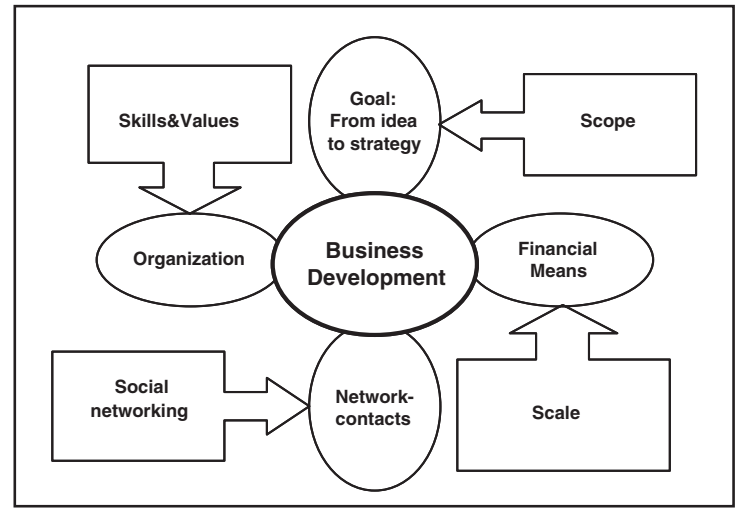

Figure 1. the 45 Social System Model of the Firm (see: Groen c.s. 2002, Groen, 2005)

guish between the levels 'Value creation within the organizational boundaries' - also referred to as corporate venturing or intrapreneuring, 'transformation of the corporate regime' - and 'transformation of the sociotechnical landscape' or 'industry rule breaking'. Although Thornberry describes the different levels as four individual, different types of entrepreneurship, it can be noted that the different levels describe more of a development process.

\section{Pattern Maintenance: Skills, Values and Arrangements Determining Organizational Characteristics}

Depending on the speed of developments in the market and the level of competitiveness a number of (non-fixed) organizational characteristics will need to be adapted to create a suitable entrepreneurial environment around the CE function. To evaluate the level of entrepreneurial attitude in the organization around the Business Development function, the present and required level of risk attitude, innovativeness and proactiveness will be determined, which combine into the level of entrepreneurial intensity (Saly, 2001). Furthermore, when looking at technology-based companies, patterns of behaviour are influenced by the state of development of the technology. Business development based on a novelty is different from settings where technology belongs to a dominant regime. The labelling of novelties as 'hopeful monstrosity' (Mokyr, In Rip \& Groen, 2001) illustrates difficulties of creating a sustainable system based on new technologies.

\section{Venturing Structures, Searching for Efficient} Investment Structures

Since companies have many types of venturing activities to choose from in order to maximally exploit the collected business opportunities, a strategy must be found to choose which type of venturing is most suitable for the corporate entrepreneurship function.

\section{Integration of CE in Dynamic Networks}

This aspect refers to the process of structuring the environment to generate sufficient opportunities for product-market combinations (Groen, During \& Weaver, 2002). Issues at hand here are the creation and maintenance of network relations. Choices have to be made on how intensive relations should be, and which position one would like to take in the network structure creating the path to the market (AOM, 2005; Burt, 1992; Granovetter, 1973).

With regard to the fourth dimension, Leleux, Tindemans and Gosselin (2002) have described seven venturing types: investments in independent venture capital funds; corporate venture capital; mentor capital (external entrepreneurs get seconded by corporate specialist); venture partnering; venture spin-offs; corporate incubators; and internal new ventures. The first four types focus on external development, whereas the last three types focus more on internal development. In a survey conducted in co-operation with Flanders Business School in around 500 Belgian companies, they investigated the links between these venturing types and the matching organizational structures and culture in a number of Belgian organizations. In this process, the following aspects were considered: size of bets, financial success metrics, funding, incentive system, strategic focus, goal, portfolio strategy, focus of work, decision-making, entrepreneurial culture and governance.

In Figure 2, the conclusions of their survey are summarized, presenting the different venturing types and the matching characteristics. The 'venturing paths' on the right-hand side of the figure can be placed over the characteristics on the left-hand side, to match the different venturing strategies with the organizational characteristics.

Many reasons are presented in literature for failure of innovation processes. All of these 'reasons for failure' present warnings for companies that wish to create a corporate entrepreneurship function for business development. As larger companies often have to deal with many parties and bureaucratic rules, execution of new projects as well as implementation of a new business function will take a great deal of time and effort (Tidd, Bessant \& Pavitt, 2001) and hence require the full attention of everyone involved, including the top management of the company. In addition, inertia in 


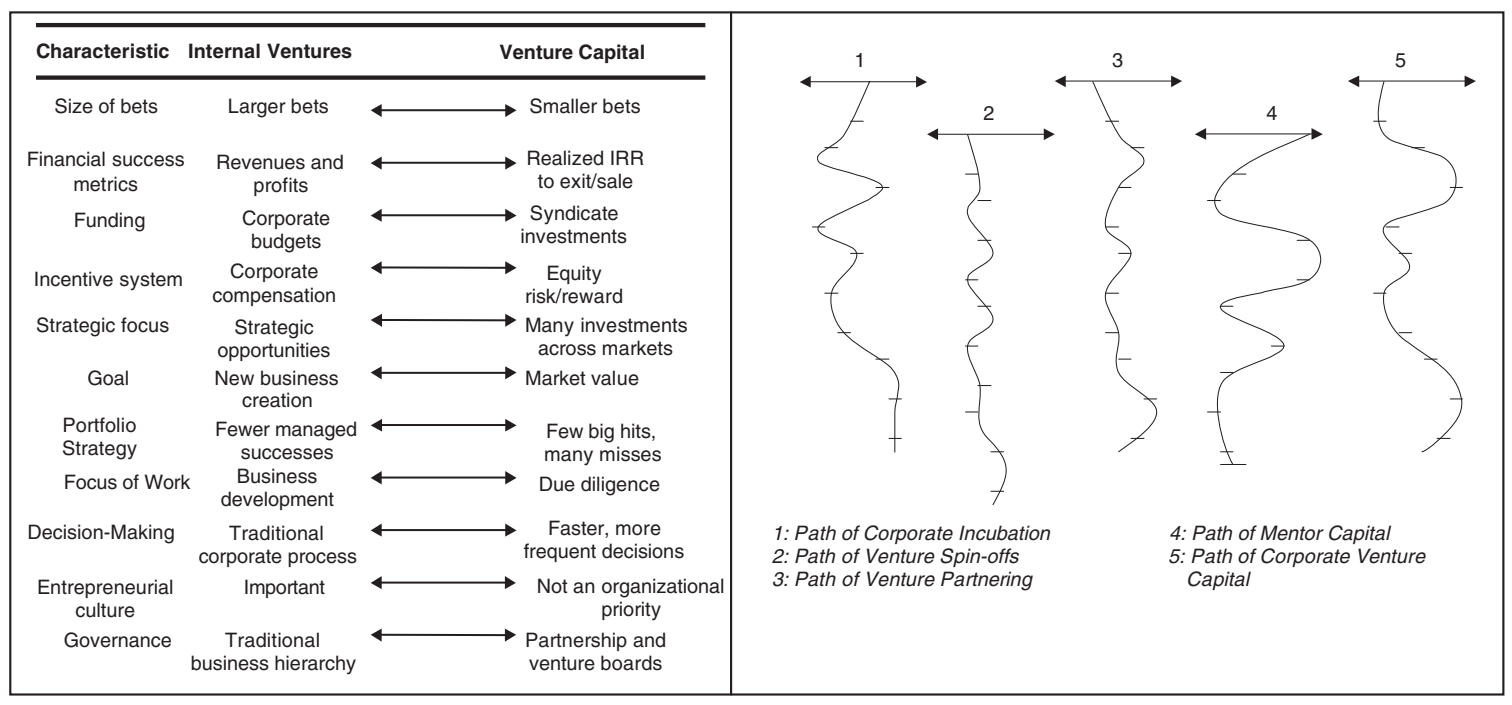

Figure 2. Venturing Strategies and Matching Characteristics

both the business processes and the decision processes, often sided by a mistaken sense of self confidence caused by former successes, heavily slow down the speed and flexibility of an organization (Stropford, 1994). Lastly, uncertainties at the front end and in the course of the innovation process might cause organizations to make wrong decisions or worse: not to take any decision at all (Lint, 2001). It is obvious that, in the process of setting up a corporate entrepreneurship function, these warnings should be considered carefully.

\section{Summarizing the Analysis of CE Functions in Five Large Firms}

To further develop a guideline for structuring corporate entrepreneurship we have carried out comparative research in five multinational high technology companies, all containing a separate Corporate entrepreneurship function to steer business development. As 'corporate entrepreneurship functions in organizations' is a relatively unexplored field in literature, we found this methodology most suitable for our research.

The studied companies operate in the chemical sector, electronics sector, processtechnology sector and food industry. At these companies, we analysed the different business development functions on the aspects mentioned above.

To gather sufficient information for the analyses we interviewed the business development directors of the five companies. During these (semi-structured) interviews several topics were discussed, corresponding to the different elements of the $4 S$ Model. In addition to these interviews, literary sources containing information about the companies were studied (annual reports and Internet sources) and the outcomes of the interviews were discussed during a second meeting at which the business development directors, as well as a number of authors and professors on the field of business development, networking theories and research and development were present. The feedback from this session has been included in the research outcomes.

\section{Results of Preliminary Cases}

From the analysis of the five different companies and our literature study, we have extracted four different types of business development: network-oriented business development, internally oriented business development, R\&D-oriented business development and business development with ad hoc idea generation. Between these types fundamental differences exist on the input side of the business development process (the process of idea generation). In network-oriented business development, market opportunities are spotted through the use of networks. These networks are used to simplify the environment in which opportunities are spotted in order to keep this process manageable. The more diversified and extended these networks, the closer this simplified environment approaches the actual one and the larger the chance to sport business opportunities. In internally oriented business development, opportunities are spotted through the other business units and the marketing department by using their contacts with the 
organizational environment. In $R \mathcal{E} D$-oriented business development, opportunities are created through the development of technological innovations, for which market possibilities have to be found. The last type, business development with ad hoc idea generation, can be described as 'market oriented without an actual idea generation strategy'. Spotting opportunities happens without a clear strategy, resulting in the fact that only a very small part of the actual business environment is scanned.

Each business development type has different features, uses a different networking strategy and requires different aspects to be present in the business configuration. By using these features and required aspects as a comparison tool, this typology turns into an instrument for the identification of problem causes in the CEF. Table 1 presents an overview of characteristics and crucial factors for each of the four types.

The company analyses revealed that a performance fit was present at three of the five companies and was not present (yet) at the other two. At the companies where the performance fit was absent, we have identified the following problems:

1. The absence of a clear networking strategy and its recognition as a formal CEF role causes lack of structural idea generation and thus limits proactiveness. As a result, only a small part of the opportunities existing in the market can be captured.

2. Insufficient analysis of environmental developments limits proactiveness.
3. Short-term financial performance measurement in combination with a high level of 'desired impact' negatively influences the chances to reach the mission and limits possibilities for radical innovation projects.

4. The positioning of the corporate entrepreneurship function under a specific business unit may result in conflicts of interest and limit innovativeness.

5. An investment portfolio that consists of a large number of smaller investments when a high-risk attitude is required decreases the chance to reach this level of risk attitude.

6. Lack of top management support in combination with an internally oriented business development strategy causes a lack of understanding in the organization, leading to conflicts of interest.

7. Inadequate communication structure in combination with an internally oriented strategy causes a lack of entrepreneurial culture and understanding in the organization, also leading to conflicts of interest.

The success factors that have been identified, based on situations where a performance fit was present, are as follows.

1. The definition of explicit business development goals and a clear strategy.

2. Creating alignment of individuals and enabling progress control and preemptive corrections.

3. Periodical progress control decreases risk.

4. Decentralization of the decision process creates speed and flexibility.

Table 1. Summary of Business Development Types

\section{Type of BD process Characteristics of BD function Crucial factors}

\begin{tabular}{|c|c|c|}
\hline Network oriented & $\begin{array}{l}\text { Central or integrated position, } \\
\text { self-created and managed } \\
\text { network }\end{array}$ & $\begin{array}{l}\text { Networking is considered a formal } \\
\text { role, a network strategy is } \\
\text { formulated, a strong reputation is } \\
\text { favorable }\end{array}$ \\
\hline Internally oriented & $\begin{array}{l}\text { Decentralized position, network } \\
\text { structure 'borrowed' from } \\
\text { other business functions }\end{array}$ & $\begin{array}{l}\text { Good communication structure, } \\
\text { sufficient power and top - } \\
\text { management support are required }\end{array}$ \\
\hline$R \& D$ oriented & $\begin{array}{l}\text { 'New to the world' - technology } \\
\text { oriented }\end{array}$ & $\begin{array}{l}\text { An extensive R\&D staff, a large R\&D } \\
\text { budget, a wide technological } \\
\text { network, sufficient patents and } \\
\text { large target markets are required }\end{array}$ \\
\hline $\begin{array}{l}\text { Ad hoc idea } \\
\text { generation }\end{array}$ & $\begin{array}{l}\text { No clear idea generation } \\
\text { strategy, inertia present or in } \\
\text { transition phase }\end{array}$ & \\
\hline
\end{tabular}


5. A strong reputation attracts possible partners and improves the idea generation process.

6. Clearly identified and specified competencies and skills excludes the HRM policy as a bottleneck for 'best possible results'.

7. Partnerships with customers stimulate idea generation and 'guarantee' a market for newly developed products.

As a part of the analyses, we have compared the study by Leleux, Tindemans and Grosselin (2001) with the outcomes of our own research findings. Overall, the findings of both studies coincided. However we have spotted a few differences, presented in Table 2. The most striking difference concerns the perception of entrepreneurial culture: the interviewed companies that use a strategy of corporate incubators consider an entrepreneurial culture important, whereas Leleux, Tindemans and Gosselin found the opposite. Further on, the companies that have a 'performance fit' (Chem1, ElecT and AquaP) link a strategy of venture spin-offs to a system of realized IRR to exit/sale as financial success metrics. They also link a strategy of internal ventures and venture partnering to fast and frequent decision-making and to partnerships and venture boards for governance.

\section{Guideline for Structured Innovation}

Based on the identified aspects of the Business Development environment the uncovered problem causes and success factors for the 'gaps' in the performance fits of the studied companies, the definition of the four business development types and the results of the survey by Leleux, Tindemans and Gosselin (2001), we have constructed a guideline. This 'guideline for structured innovation' is depicted in Figure 3.

The top centre of the guideline is formed by the factor ' $\mathrm{CE}$ intensity'. As described in the theoretical background section, this factor represents the desired and actual level of innovativeness, proactiveness and risk attitude. The CE intensity is influenced by the business development mission, the organizational environment and the organizational characteristics.

The aspects of the business development mission that influence the CE intensity are the level of 'desired impact of the developed innovations' and the time horizon that the mission covers (short term/long term). In general, the more ambitious and long term the mission, the higher the required level of $\mathrm{CE}$ intensity. Shorter-term missions with a lighter desired impact are usually focused on short-

Table 2. Identified Links between Innovation Strategies and Organizational Characteristics

\begin{tabular}{|c|c|c|c|c|}
\hline Company & $\begin{array}{l}\text { Venturing } \\
\text { strategy }\end{array}$ & $\begin{array}{l}\text { Organizational } \\
\text { characteristic }\end{array}$ & $\begin{array}{l}\text { Suggestion } \\
\text { Tindemans et al. }\end{array}$ & $\begin{array}{l}\text { Identified } \\
\text { characteristic }\end{array}$ \\
\hline Case 1 & $\begin{array}{l}\text { Corporate } \\
\text { incubators Corp. } \\
\text { venture capital } \\
\text { Venture spin-offs }\end{array}$ & $\begin{array}{l}\text { Success metrics } \\
\text { Entrepreneurial } \\
\text { Culture }\end{array}$ & $\begin{array}{l}\text { Revenues \& Profits } \\
\text { Not an organizational } \\
\text { priority }\end{array}$ & $\begin{array}{l}\text { Realized IRR to } \\
\text { exit / sale } \\
\text { Important }\end{array}$ \\
\hline Case 2 & $\begin{array}{l}\text { Corporate } \\
\text { incubators }\end{array}$ & $\begin{array}{l}\text { Incentive system } \\
\text { Scope } \\
\text { Entrepreneurial } \\
\text { Culture }\end{array}$ & $\begin{array}{l}\text { Equity risk / reward } \\
\text { Strategic opportunities } \\
\text { Not an organizational } \\
\text { priority }\end{array}$ & $\begin{array}{l}\text { Corporate } \\
\text { compensation } \\
\text { Many } \\
\text { investments } \\
\text { Important }\end{array}$ \\
\hline Case 3 & $\begin{array}{l}\text { Corporate } \\
\text { incubators }\end{array}$ & $\begin{array}{l}\text { Entrepreneurial } \\
\text { Culture }\end{array}$ & $\begin{array}{l}\text { Not an organizational } \\
\text { priority }\end{array}$ & Important \\
\hline Case 4 & $\begin{array}{l}\text { Internal ventures, } \\
\text { Corporate } \\
\text { incubators }\end{array}$ & $\begin{array}{l}\text { Scope } \\
\text { Goal }\end{array}$ & $\begin{array}{l}\text { Strategic opportunities } \\
\text { New business creation }\end{array}$ & $\begin{array}{l}\text { Many } \\
\text { investments } \\
\text { Market value }\end{array}$ \\
\hline Case 5 & $\begin{array}{l}\text { Internal ventures, } \\
\text { Venture partnering }\end{array}$ & $\begin{array}{l}\text { Decision-making } \\
\text { Governance }\end{array}$ & $\begin{array}{l}\text { Traditional corporate } \\
\text { process } \\
\text { Traditional hierarchy }\end{array}$ & $\begin{array}{l}\text { Fast, frequent } \\
\text { decisions } \\
\text { Partnerships and } \\
\text { venture boards }\end{array}$ \\
\hline
\end{tabular}




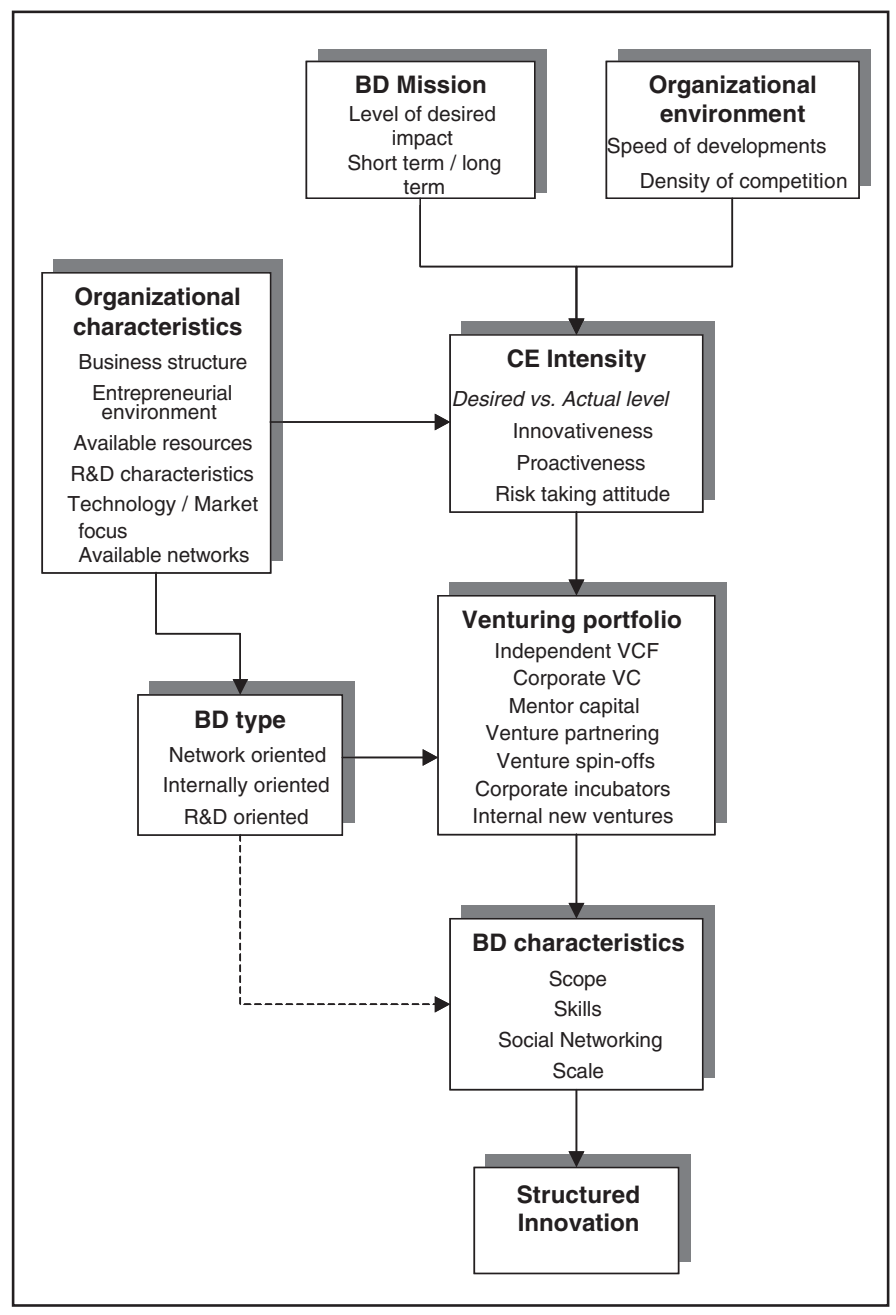

Figure 3. Guideline for Structured Innovation

term financial goals, and require a lower level of innovativeness and risk attitude. The aspects of the environment that have an impact on the CE intensity are the speed of developments (dynamic aspects) and the density of competition that the organization has to deal with. The stronger both aspects, the higher the level of required innovativeness and proactiveness.

The organizational characteristics that influence the $\mathrm{CE}$ intensity are the aspects that determine the limiting conditions for the business development environment. These aspects are (to a certain extent) the business structure, the available resources and the $R \& D$ characteristics (focus of research). The focus on technological or market-oriented innovation, the availability of networks and the presence of an entrepreneurial environment are also aspects that influence the CE intensity. These aspects are part of the fixed organizational characteristics, as it is very difficult to change them completely, and therefore they influence the realizable level of CE intensity.

To determine the required level of CE intensity, all three of these factors need to be considered, and no problems should be caused by contradictory aspects. As an example, at one of the companies we analysed, the business development mission requires a level of $\mathrm{CE}$ intensity that is appropriate for the creation of innovations that have an impact of 'organizational transformation'. In the current business structure however, the business development function is placed under a business unit whose mission is defined as to 'concentrate on improving returns and cash flow'. This causes a conflict regarding the aspect short term/long term.

With the information about the organizational characteristics, the most suitable business development type can be determined. As 
described in Table 1, the suitability of the type depends on the position of the function in the organization, the available network structures, the R\&D characteristics and the available resources. Based on these aspects, the company can choose to implement a structure that resembles either the network oriented, internally oriented, R\&D oriented or ad hoc oriented business development model.

The next step in the process is to determine an appropriate venturing portfolio. Considering the identified differences between the outcomes of the interviews and the results of the survey conducted by Leleux, Tindemans and Gosselin (2001), the following modifications to the Venturing Strategies model (Figure 2) are suggested:

- corporate incubators should be linked to an emphasis on entrepreneurial culture;

- venture spin-offs could be linked to a system of realized IRR to exit / sale as financial success metrics;

- internal ventures and venture partnering could be linked to fast and frequent decision-making, as well as to partnerships and venture boards for governance.

Since the first suggestion is supported by all three of the companies with a 'performance fit', we can be more certain about modification of the model than we can be for the other two suggestions. For all three suggestions however, more research is needed to confirm them. Keeping these three suggestions in mind, and the fact that the other links between innovation strategies and organizational characteristics (as suggested by Leleux, Tindemans and Gosselin) are supported by the outcomes of this research study, this model can be used as a tool for generating advice for the composition of the innovation portfolio and the way the organization should support the venturing strategy.

As a final step in the guideline, the composition of the venturing portfolio combined with the choice of business development type and the identified problem causes and success factors can be used to present recommendations regarding the characteristics that should be present in the business configuration.

In the next section, this 'guideline for structured innovation' is applied on the company of our study: Process ${ }^{\mathrm{TM}}$.

\section{Case: Process ${ }^{\mathrm{TM}}$}

\section{Introduction}

Process $^{\mathrm{TM}}$ is a medium-sized company that operates worldwide in the development and application of process technologies. It supplies products, installations and services for, amongst others, the food and beverage industry, automotive industry, chemical industry, pharmaceutical industry and water industry. In the served market segments, Process ${ }^{\mathrm{TM}}$ owns large market shares. Process ${ }^{\mathrm{TM}}$ has an annual turnover of a few hundred million euros, and production and construction facilities in several countries throughout the world. With sales offices and a distribution network in more than 100 countries a global coverage is provided. In its mission statement, Process ${ }^{\mathrm{TM}}$ focuses on developing and applying state-ofthe-art technologies to create innovative products, systems and technological solutions to help society - through its clients - to meet environmental and health and safety challenges. Through relationships with customers, world-class employees and access to the leading process technologies across the world, Process $^{\mathrm{TM}}$ achieves long-lasting leadership for its customers and world leadership in the global processing industry. This mission statement shows both the company's goal (global leadership in the served markets) and its strategy (developing technological solutions through customer orientation) as well as its core assets (state-of-the-art technology and the use of world-class employees).

As mentioned in the introduction, the company has recently expressed the need for a separate business development function and by following the guideline we will present recommendations on how to create this function in a matching organizational environment. Data on the current state of affairs is generated by secondary analysis of documents and interviews with key employees as well as regular discussions with the business development director.

The current business development activities of Process ${ }^{\mathrm{TM}}$ can be described, using the $4 \mathrm{~S}$ social system model. This description includes (as described above) information about goals and strategies, skills, routines and competencies, internal and external network partners and financial control. Aware of the fact that global competition is increasing every year, the general management of Process ${ }^{\mathrm{TM}}$ has created a budget for 'business development' in order to create an effective corporate entrepreneurship function. The goal of the CEF is to 'assure revenues and profits in the long term' and to 'maintain global leadership'. This task has been put in the hands of the Business Development Director. Since the Business Development Director manages the waterprocessing activities of Process $^{\mathrm{TM}}$ at the same time, the business development activities are primarily focused on this industry, and 
include a number of activities: based on the input that is received from the market a homogeneous opportunity is spotted, which is evaluated on three points: market attractiveness, fit with core competencies and fit with company strategy. After the opportunity has passed these three 'tests', a project team is formed, and the idea is taken into the development stage. Often development takes place in close contact with customers.

No explicit goals have been formulated for the corporate entrepreneurship function, so it is not clear forehand which outcomes of the business development processes are aimed for. When opportunities are spotted and evaluated, they are presented to the general management, which gives its (dis-)approval. Out of each ten ideas that are presented, around six are approved. With the exception of this approval phase, general management has no real involvement in the business development process; moreover, it has no clear vision of which activities the business development process contains.

Contact with general management and other departments is mostly informal, and although regular contact exists with Marketing \& Sales and R\&D, they have 'no real idea' what business development involves. As mentioned, the technological knowledge that is present in the company is a unique skill that provides a competitive advantage and can insure competitive sustainability in the future. Being a technology driven company, many opportunities arise from the R\&D department. However, the largest percentage originates at the market side and reaches Process ${ }^{\mathrm{TM}}$ through several networks.

Networking takes place both in a structural way and on an 'ad hoc' basis. Through participation in several networks and through 'active environmental scanning' opportunities are spotted. The tools that are used for environmental scanning are trend analysis, scenario analysis and general scanning of market developments.

The only economic income of the business development function is the budget that has been made available by top management. This budget however, is relatively small. No specific method is used for financial control.

To summarize, the characteristics of the business development function can be described with the following key words: a small number of large-sized bets, looking for strategic opportunities, revenues and profits as financial success metrics, corporate funding as sole economic income, a mixture between corporate compensation and equity risk/ reward as an incentive system, a focus on market value instead of new business creation, fast decision-making and a mixture between traditional hierarchy and venture boards for governance.

\section{Evaluation of the CE Function}

Through the 'guideline for structured innovation', an analysis of the (f)actors and relationships within Process ${ }^{\mathrm{TM}}$ will lead to recommendations concerning the creation of an effective business development function in an entrepreneurial environment. In this process, the following steps will be taken:

1. Definition of the business development mission;

2. Description of the organizational environment;

3. Definition of relevant organizational characteristics;

4. Determination of the required and current level of CE intensity;

5. Determination of the appropriate business development type;

6. Determination of the appropriate venturing strategy;

7. Presentation of recommendations for required characteristics of the business development function.

\section{Step 1-2-3: Mission, Environment and Organizational Characteristics}

In terms of the guideline, the Mission of Process $^{\mathrm{TM}}$ can be described on the basis of 'level of impact' and 'space of time'. As described, the mission of Process ${ }^{\mathrm{TM}}$ contains the goal of 'global leadership' and management has indicated a time-scale of around five to seven years. Figure 4 presents the current and desired situation. It shows which routes newly developed technologies can take and which impact on their environment they can have (Rip \& Groen, 2001).

In this figure is illustrated that the following years may be crucial to whether Process ${ }^{\mathrm{TM}}$ 's technologies will modify the process technology landscape (third layer). This statement is supported by the fact that water processing is currently a 'hot topic' and receives a lot of attention throughout the world. In the past it has occurred many times that evolving (high technology) markets adopt one main technology and other technologies have to struggle for survival.

Another aspect of the organizational environment is the fact that the lifecycle of waterprocessing systems is relatively short. Once implemented however, a customer is not likely to switch suppliers very easily. Also, global competition is increasing, meaning that 


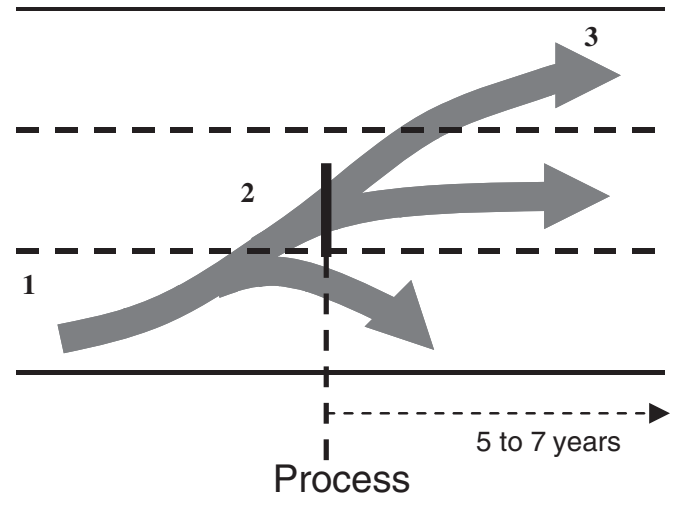

1. Novelty, shaped by existing regime

2. Evolves, is taken up, may modify regime

3. Landscape is transformed

Figure 4. Routes of Newly Developed Technologies

customers have an increasing number of options. Based on these two facts, the discovery of new markets can be very lucrative (firstmover advantage).

The following relevant organizational characteristics can be extracted from the information, presented about Process ${ }^{\mathrm{TM}}$ : in the organizational structure, the business development function is divided under the division that focuses on water processing, $R \& D$ activities are focused around a number of technology platforms, business development activities are both $R \& D$ and market oriented, the business development function has created its own network environment, based on contacts with existing partners and through developing new links on an ad hoc basis (no network strategy is present). The organizational culture can be described as 'moderately innovative': the need for innovation has been acknowledged but the business development function is hardly facilitated.

\section{Step 4: Required and Current Level of CE Intensity}

The next step in the process of creating a CEF is the definition of the desired and present level of intensity of corporate entrepreneurship. First, however, possible internal conflicts in the current situation should be identified. In the case of Process ${ }^{\mathrm{TM}}$, a conflict could be caused by the goals that top management has set when the budget for business development has been created. 'Assuring revenues and profits in the long term' and 'global leadership' are goals that can be achieved together, but may require two different levels of risk attitude. Next, the fact that the business development function is currently placed under a specific division limits the business development activities to the field of water processing and it will be difficult to expand to other fields of technology in the current structure.

The required level of $\mathrm{CE}$ intensity influences the decision-making process concerning the configuration of the business development environment. Based on the characteristics of the mission, the environment and the organization, the required $\mathrm{CE}$ intensity can be determined.

The mission statement clearly states that Process ${ }^{\mathrm{TM}}$ wishes to achieve and/or maintain world leadership with its technologies. The environment has been defined as highly competitive with high 'switch-over' boundaries. This means that a high level of proactiveness concerning both potential customers and environmental developments is needed in order to observe the actions of competitors and develop new market segments. The required level of innovativeness is medium to high, to stay ahead of competitors and to serve a growing number of market segments, based on the existing technology platforms. As stated above, the goals for business development 'global leadership' and 'long-term revenue guarantee' require two different levels of risk attitude. However, when a certain risk is accepted for the goal 'revenue guarantee' the two goals can be combined. Combined with the fact that Process ${ }^{\mathrm{TM}}$ is a medium-sized company, operating in a rapidly growing environment, the required risk attitude can be defined as medium to high.

To determine the actual levels of innovativeness, proactiveness and risk attitude, the current configuration and business practices are reviewed. The foundation of the business development function and the several innovative projects show that innovative behaviour is present, but the lack of communication with top management and other business functions, together with the low level of compre- 
hension of the business development activities make clear that innovativeness is not integrated throughout the company yet. Therefore, the level of innovativeness is defined as medium to low. The continuous scouting for network opportunities by the business development function to develop market opportunities show that 'being proactive' is recognized as important by the business development function. However, no real network strategy has been defined, neither has networking been recognized as a formal role by top management. Concluding, proactiveness is defined as medium to low. The current venturing strategy can be described as a small number of large-sized bets, in search of strategic opportunities. Top management demands little control concerning innovative investments, but new opportunities have to match with the current business strategy. Based on these facts, risk attitude can be defined as medium to high.

When we compare the actual level of CE intensity with the required level, it can be concluded that the levels of both innovativeness and proactiveness need to increase. The implications of this conclusion for Process ${ }^{\mathrm{TM}}$ will be discussed later.

\section{Step 5: Business Development type}

To determine which business development type is most suitable for Process ${ }^{\mathrm{TM}}$ and which crucial factors should be present at the business development function, the organizational characteristics are compared to the characteristics of the different business development configurations.

Since the $R \& D$ function at Process ${ }^{\mathrm{TM}}$ does not produce a continuous flow of 'new-to-theworld' technologies on which the company's innovation policy is (or can be) based, the R\&D oriented Business Development is not suitable for Process ${ }^{\mathrm{TM}}$. The network-oriented type on the other hand, like Process ${ }^{\mathrm{TM}}$, focuses on the creation of new market opportunities. The business development function of Process $^{\mathrm{TM}}$ creates and manages its own network, which has been listed as a demand for network-oriented business development. However, since the business development function has been placed under the water-processing division, the field of innovation is restricted to water-processing technology. If the business development function wishes to expand its activities with the current position in the organizational structure, it will need to communicate much stronger with other divisions: however, a more central position in the organization is preferable. Lastly, since a strong focus is put on 'customer-oriented' innova- tions, the business development function needs to communicate structurally with the sales and marketing business functions. It can be concluded that the business development configuration should be a combination of network-oriented and internally oriented business development. As presented in Table 1 the crucial factors for these two types are:

- networking is considered a formal role;

- a network strategy is formulated;

- a strong reputation is favorable;

- a good communication structure is required;

- the business development function must have sufficient power to execute projects among the 'everyday business processes' of the other organizational parts;

- top management support should provide this power.

\section{Step 6: Venturing Strategy}

Currently, the venturing strategy of Process ${ }^{\mathrm{TM}}$ focuses on internal ventures. For this type of venturing, the innovation process must be carried out among the everyday business processes. This requires a great deal of understanding and support by the entire organization. In the current configuration of Process $^{\mathrm{TM}}$, this understanding and support is absent. Combined with the fact that no system has been created for financial control of the business development activities, the mediumto-high risk attitude is not controlled, and this creates uncertainty. At the same time, top management will have difficulties in keeping a view of the total situation, and knowledge management (and knowledge delegation to successors) is obstructed.

A type of venturing that needs less integration in the organization is corporate incubation, whereby new ventures are provided sufficient leeway to operate relatively independent in a 'cocoon' of corporate support and services. This description seems less far from the current situation, but still requires top management support, and moreover a larger budget to pursue different opportunities. Observing the characteristics that are commonly used for both types of venturing (according to the study by Leleux, Tindemans and Gosselin (2001), with the proposed changes taken into account), it can be concluded that the current business configuration more closely resembles the characteristics of corporate incubation than those of internal venturing. This is shown in Figure 5, in which the thin line represents the characteristics, belonging to corporate incubation and the thick line represents the current characteristics 


Size of bets
Financial success
metrics
Funding
Strategic focus
Focal

Figure 5. Business Development Characteristics of Process ${ }^{\mathrm{TM}}$

of Process ${ }^{\mathrm{TM}}$. The left-hand side of the figure belongs to internal venturing. This figure can function as a tool for the decision between the two innovation strategies.

\section{Step 7: Recommendations}

Following the structure of the 'guideline for structured innovation', the analysis of Process $^{\mathrm{TM}}$ 's Business Development function has resulted in a number of issues regarding the creation of an entrepreneurial environment. First of all, the question should be asked whether the business function should be placed under a specific division or should be given a more central position in the company. Next, the level of innovativeness and proactiveness has to increase. The relationships with top management and the other business functions have to be reviewed and adapted and the 'crucial factors', mentioned in the analysis of business development types need to be present in the configuration. Lastly, a decision has to be made concerning the type of venturing and the implications for the configuration that follow from this decision have to be dealt with.

To increase the level of proactiveness, a specific network strategy has to be defined. This strategy should include information about which network partners are relevant, how these networks will be created and which ties must be kept strong/weak. A budget has to be available for networking, recognizing it as a formal task. Periodically, progress should be reviewed. To increase the level of innovative behavior, top management needs to be well informed about Business Development activities and should be involved in the creation of a business development strategy for the coming five years. By planning periodical progress reviews, top management will stay informed. Based on these reviews, appropriate budgets can be assigned.

The uncertainty, following from the high level of risk, can also be controlled through these reviews. 'Public' support by top management and an appropriate communication structure will create understanding for business development activities throughout the company and will support both the creation of opportunities and co-operation for innovation projects.

By implementing these changes, all of the 'crucial factors' for the described business development type will be present. To create a 'strong reputation' in the relevant environment, networking and marketing are the appropriate instruments. Extra aspects of the business configuration that will have a positive effect on the performance of the business development function, following from the identified success factors, are the formulation of explicit business development goals and strategy, combined with periodic progress reviews, a suitable financial control system 
and sufficient sources of economic income, a large pool of available experts and clearly identified skills and competencies of project team members.

Based on the observation that the current business development configuration has more similarities with the recommended configuration for corporate incubation than for internal venturing, the first option is recommended as venturing strategy. This means that the business development function should create fairly independent project teams for innovation projects. These project teams have to be fully supported by corporate management and be provided with sufficient leeway to perform their tasks.

\section{Conclusions}

In this article we have described a guideline and some background for creating a corporate entrepreneurship function in order to realize business development in a high-tech context. It was illustrated using the case of the company Process ${ }^{\mathrm{TM}}$, which has expressed to desire to become market leader in their market through innovation. Our research question was: how can an effective corporate entrepreneurship function (CEF) be developed in a medium-sized technology based company?

At the moment, there is no general guideline available in literature. So the first contribution of the research supporting this article was to construct such a guideline based on elements of the body of knowledge in this area. Using as a basis the $4 \mathrm{~S}$ social system perspective (Groen, 2005; Groen, During \& Weaver, 2002), adding several literary sources for further operationalization of elements, we found a list of success and fail factors for creating a CEF. The empirical study of Leleux, Tindemans and Gosselin (2001) corroborated most findings. Based on the five cases used for developing the guideline it should be noted that the business processes and competitive environment are different in every organization. Still, the communalities in the cases and elements found in literature make it justifiable to assume that the presented guideline contains elements that are crucial in every 'process of structuring innovation'.

Through the use of examples of the research outcomes it has been shown in which way the guidelines are linked to the organizations. The illustrative case study of Process ${ }^{\mathrm{TM}}$ shows that also in this case all elements point out relevant questions for the management of the CEF. Although only applied to this one case, the theoretical background and the results in this case suggest that this guideline can also be applied to other medium or large-sized companies that wish to create structured business development processes. However, this guideline is neither a 'ten steps to success' - model, nor a summary of ideas that business development managers can interpret any way they want to. It shows a sequence of factors that have to be considered in the process of implementing a suitable business development process and matching environment.

Still more research is needed to test validity and reliability of the proposed guideline. Indepth data on more companies will have to be found in next studies. In these studies further theoretical developments will also be made to develop a more specified multi-dimensional and network management-oriented analytical tool including a performance measurement.

\section{Reference}

Badguerahanian, L. and Abetti, P.A. (1995) 'The rise and fall of the Merlin-Gerin foundry business, a case study in French corporate entrepreneurship', Journal of Business Venturing, 10, 477-93.

Barringer, B.R. and Bleudorn, A.C. (1999) 'The relationship between corporate entrepreneurship and strategic management', Strategic Management Journal, 421-44.

Christensen, C.M. (2003) The Innovator's Dilema, Harvard Business Press, Harvard.

Groen, A.J., de Weerd Nederhof, P.C., Kerssens-van Drongelen, I.C., Badoux, R.A.J. and Olthuis, G.P.H. (2001a) 'Leveraging Research and Development. Creating and Justifying Added Value'. Proceedings of 'Leveraging R\&D' R\&D Management Conference, New Zealand, 8-9 February.

Groen, A.J., de Weerd Nederhof, P.C. and Kerssensvan Drongelen, I.C. (2001b) 'Leveraging Research and Development, using the 4S model'. Proceedings, EIASM Conference on NPD.

Groen, A.J., During, W.E. and Weaver, K.M. (2002) 'Alliances between HTSF's and their partners: a multidimensional process approach'. In Oakey, R., During, W.E. and Kauser, S. (eds), New technology-based firms in the new millennium - volume II, pp. 197-217.

Groen, A.J. (2005) 'Knowledge Intensive Entrepreneurship in Networks: A Multi-level / multi dimensional approach based on social system theory', Journal of Enterprising Culture, March.

Leleux, B., Tindemans, B. and Gosselin, D.P. (2001) Bringing Entrepreneurship Inside: Venturing for Growth. Working Paper, Flanders Business School - IMD Lausanne.

Lint, O. (2001) Measuring and Managing RED Option Value. Ridderkerk: Offsetdrukkerij Ridderprint B.V.

Rip, A. and Groen, A.J. (2001) Many visible hands. In Cooms, R., Green, K., Richards, A. and Walsh, V. (eds), Technology and the market. Demand, user and innovation, pp. 13-37.

Saly, A.W. (2001) Corporate Entrepreneurship, antecedents and consequences of entrepreneurship in large 
established firms. Rotterdam: Tinbergen Institute Research Series.

Schumpeter, J.A. (1934) The theory of economic development. Harvard University Press, Cambridge, MA.

Stropford, J.M. (1994) 'Creating Corporate Entrepreneurship', Strategic Management Journal, 15(7), 521-36.

Thornberry, N.E. (2002) 'Corporate Entrepreneurship: teaching managers to be entrepreneurs', Journal of Management Development, 22(4), 329-44.

Tidd, J.K., Bessant, J. and Pavitt, K. (2001) Managing Innovation, 2nd edn. John Wiley \& Sons Ltd, Chichester.

Weerd-Nederhof, de P.C. (1998) Operational New Product Development Systems. Operational Effectiveness and Strategic Flexibility. Unpublished thesis, University of Twente, Enschede.
Aard Groen is institute director of NIKOS, the Dutch Institute for Knowledge Intensive Entrepreneurship, and associate professor at the University of Twente and Saxion professional University. His research is focused on knowledge intensive entrepreneurship in networks, studied using a social system theoretical perspective. Groen chairs the High Tech Small Form conference bi-annually in Enschede, and is member of several entrepreneurship committees at the EFMD, European Foundation for Management Development, ECIU, European Consortium of Innovative Universities and BEPART, the Baltic Entrepreneurship Partnership. He received his master on public administration from the University of Twente, and his $\mathrm{PhD}$ on business administration from the University of Groningen. Groen has published several articles and chapters on innovation and entrepreneurship.

Lute Broens is business development manager of NORIT, in the area of membrane technology for water purification. Before working for NORIT he started companies in membrane technology and other fields of high-tech business. Currently he is also involved in a worldwide network of water-related industries and NGOs.

Boaz Uittenbogaart studied industrial engineering and management at the University of Twente. For his masters thesis he performed (under the supervision of Professor Groen) the study that is basis for this article. Currently he works as a financial analyst for a large retail bank in the Netherlands. 